\title{
Structure-Activity Relationships of GAG Mimetic-Functionalized Mesoporous Silica Nanoparticles and Evaluation of Acyclovir-Loaded Antiviral Nanoparticles with Dual Mechanisms of Action
}

Edward C. Lee, ${ }^{\dagger}$ Chau T. H. Nguyen, ${ }^{\dagger}$ Ekaterina Strounina, ${ }^{\ddagger}$ Nicholas Davis-Poynter, ${ }^{*}, \S$ and Benjamin P. Ross $* \dagger+(0$

${ }^{\dagger}$ School of Pharmacy and ${ }^{\ddagger}$ Centre for Advanced Imaging, The University of Queensland, Brisbane, Queensland 4072, Australia

${ }^{\S}$ Centre for Children's Health Research, The University of Queensland, 46 Graham Street, Brisbane, Queensland 4101, Australia

Supporting Information

ABSTRACT: Mesoporous silica nanoparticles (MSNs) are drug delivery agents that are able to incorporate drugs within their pores. Furthermore, MSNs can be functionalized by attachment of bioactive ligands on their surface to enhance their activity, and nanoparticles modified with glycosaminoglycan (GAG) mimetics inhibit the entry of herpes simplex virus (HSV) into cells. In this study, structure-activity relationships of GAGs attached to MSNs were investigated in relation to HSV-1 and HSV-2, and acyclovir was loaded into the pores of MSNs. The sulfonate group was demonstrated to be essential for antiviral activity, which was enhanced by incorporating a benzene group within the ligand. Loading acyclovir into GAG mimetic-functionalized MSNs reduced the viral infection, resulting in nanoparticles that simultaneously target two distinct viral pathways, namely, inhibition of viral entry and inhibition of DNA replication.

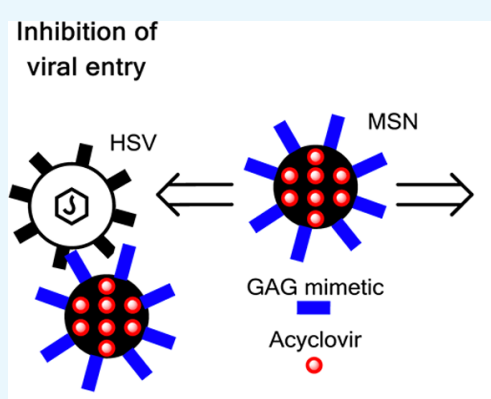

Inhibition of viral DNA replication

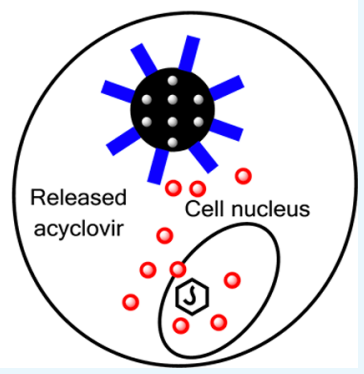

\section{INTRODUCTION}

Herpes simplex virus (HSV) causes numerous infectious diseases including orolabial herpes and genital herpes. ${ }^{1}$ In the clinic, these infections are currently managed symptomatically using guanine analogues such as acyclovir, valaciclovir, and famciclovir, which inhibit viral DNA replication. ${ }^{1}$ There have been no further major advances in the pharmacotherapy of HSV infections since the discovery of guanine analogues in the late 1970s. ${ }^{2,3}$ Guanine analogues are unable to eradicate viruses from the host following primary infection, with the HSV prevalence remaining high globally. ${ }^{3}$

Both HSV-1 and HSV-2 initiate infection of cells by interacting with receptors on the cell surface that mediate viral entry. 4,5 The initial interaction is believed to be due to the electrostatic and hydrophobic interaction of viral glycoprotein (gB or gC) with host cell glycosaminoglycans (GAGs) (e.g., heparan sulfate) composed of negatively charged sulfonate groups linked by hydrophobic moieties. ${ }^{4-8}$ Shukla et al. determined that heparan sulfate modified by 3-O-sulfotransferases may also be involved in the subsequent step of viral entry, virus fusion with cell membrane, by binding to HSV-1 $\mathrm{gD} .^{9} \mathrm{HS}$ is therefore also involved in the latter stages of viral entry of HSV, similar to the entry mechanism of human immunodeficiency virus. ${ }^{10}$ Molecules that mimic GAGs can inhibit HSV entry into cells; hence, GAG mimetics have the potential to become a new class of antiviral agent for prophylaxis of HSV infections. ${ }^{11,12}$

There is great interest in nanoparticles as drug delivery agents because of their many favorable properties including a high surface area-to-volume ratio, which can support high concentrations of bioactive ligands on their surface whilst maintaining a small volume. ${ }^{13}$ Using silver, gold, and albumin nanoparticles, the antiviral activity of simple alkyl sulfonate GAG mimetics against HSV-1 was substantially enhanced. ${ }^{14-16}$ In our recent study, an aryl sulfonate GAG mimeticfunctionalized onto mesoporous silica nanoparticles (MSNs) was demonstrated to have low toxicity and inhibit the entry of HSV-1 and HSV-2 into susceptible cells, whereas unfunctionalized MSNs and the GAG mimetic alone were inactive. ${ }^{17}$ However, an investigation into the structure-activity relationship (SAR) of functional groups attached to MSNs in the context of anti-HSV activity has not been explored. Hence, in this study, we modified MSNs with various functional groups related to the GAG structure and investigated their SARs against HSV-1 and HSV-2 infection of susceptible cells. MSNs were selected as the drug delivery vehicle because their highly ordered mesoporous interior and large pore volume (0.6-1

Received: October 28, 2017

Accepted: January 24, 2018

Published: February 9, 2018 
$\mathrm{cm}^{3} \mathrm{~g}^{-1}$ ) can accommodate large amounts of loaded drugs, even exceeding 30 wt \%. ${ }^{18}$ This distinguishing and valuable feature of MSNs, combined with their thermal stability, mechanical resilience, and surface silanol groups that enable facile attachment of organic groups, has enabled the development of highly sophisticated multifunctional drug delivery systems for various diseases. ${ }^{19,20}$

In the second part of this study, we explored MSNs loaded with acyclovir and functionalized with a GAG mimetic to simultaneously target two distinct viral pathways, namely, inhibition of viral entry and inhibition of DNA replication (Figure 1). Silicon-based materials have previously been used to

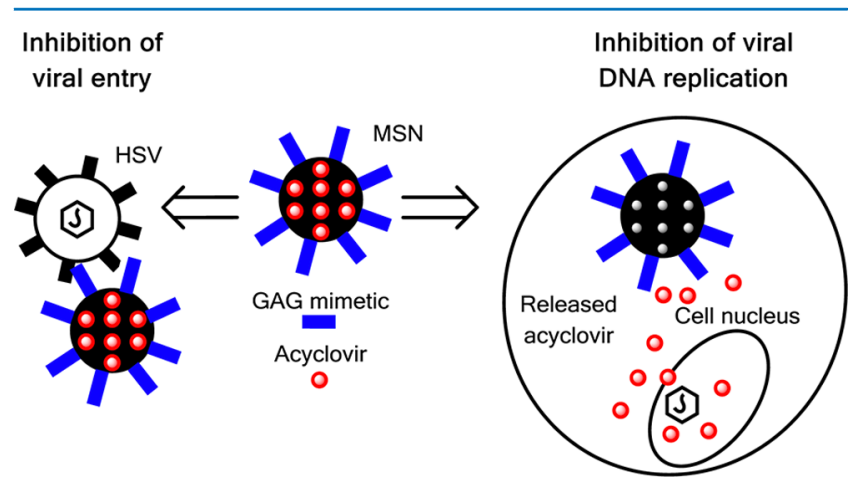

Figure 1. Proposed multifunctional MSNs that are able to bind to extracellular HSV via the GAG mimetic to inhibit viral entry and inhibit intracellular processes of viral infection by blocking viral DNA replication through the release of acyclovir.

load acyclovir, and their drug release properties were studied. $^{21,22}$ However, to the extent of our knowledge, this is the first time that acyclovir has been loaded into GAG mimeticfunctionalized MSNs. Such multifunctional systems that act on more than one viral target may slow down the emergence of drug-resistant viruses. Furthermore, loading acyclovir into MSNs may help to improve its delivery because it suffers from poor oral bioavailability and topical preparations have poor penetration to the dermis, leading to inadequate response in the treatment of orolabial herpes. ${ }^{23}$ Indeed, nanoparticles other than MSNs have been used to improve the delivery of acyclovir for the treatment of HSV infections such as orolabial herpes, ${ }^{23}$ genital herpes, ${ }^{24}$ and ocular keratitis. ${ }^{25,26}$ For example, acyclovir-loaded polymeric nanoparticles have demonstrated increased potency compared to the free drug, possibly because of the intracellular uptake of the nanoparticles and subsequent release of the loaded drug. ${ }^{27}$

Herein, we report the SARs of GAG mimetic-functionalized MSNs in relation to HSV-1 and HSV-2 infection of susceptible cells. Furthermore, we demonstrate the dual mechanism of action against HSV-1 and HSV-2 by GAG mimetic-functionalized MSNs loaded with acyclovir (Figure 1).

\section{RESULTS AND DISCUSSION}

Synthesis of MSNs (1). MSNs (1) were synthesized by the base-catalyzed hydrolysis-condensation reaction of tetraethylorthosilicate (TEOS) in ethanol with cetyltrimethylammonium bromide $(\mathrm{CTAB})$ as the structure-directing agent using a protocol adapted from Kim et al. ${ }^{28}$ The nanoparticles (1) were generally well-dispersed (Table S1), providing a greater available surface area for functionalization. As illustrated in Scheme 1, the MSNs (1) were subsequently functionalized with GAG mimetics $(3,5$, and 6$)$ or groups that are structurally related to GAG mimetics (4 and 7) to elucidate SARs.

Benzene Sulfonate-Functionalized MSNs (3). Using a method derived from our previous study, ${ }^{17}$ MSNs (1) were functionalized with sodium benzene sulfonate at various degrees of functionalization (DFs) to form nanoparticles of $100-150 \mathrm{~nm}$ in diameter (MSN-phenyl-SO ${ }_{3}$ ) (3) (Figure 2A). This GAG mimetic was selected because it is the simplest form of aromatic sulfonate and MSNs functionalized with this group were previously demonstrated to inhibit the entry of HSV into susceptible cells. ${ }^{17}$ The morphology of the nanoparticles was visualized by transmission electron microscopy (TEM), and their size was estimated using dynamic light scattering (DLS). The zeta potentials of all three analogues of MSN-phenyl- $\mathrm{SO}_{3}$ (3) in aqueous suspension were less than $-40 \mathrm{mV}$, which is likely to confer good colloidal stability because of the interparticle repulsion. ${ }^{29}$ The density of the attached sodium benzene sulfonate group was varied by changing the concentration of 2-(4-chlorosulfonylphenyl)ethyltrimethoxysilane (CSPTMS) during the preparation of

Scheme 1. Functionalization Reactions Used To Prepare MSNs Comprising GAG Mimetics (Blue Boxes) or Functional Groups Related to the GAG Structure (Green Boxes)

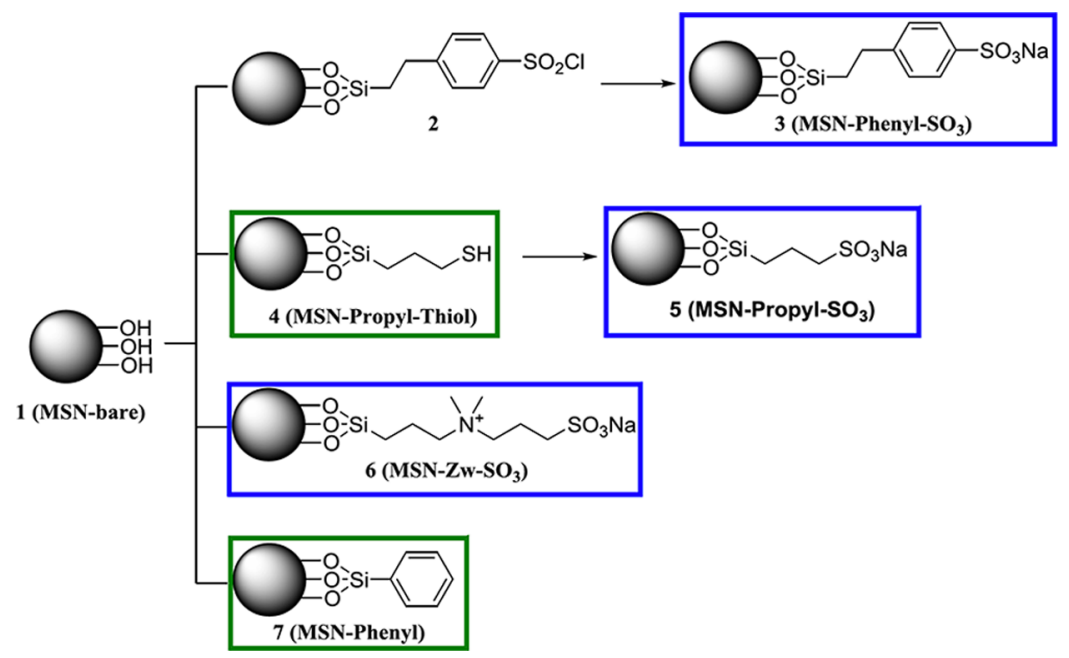


A
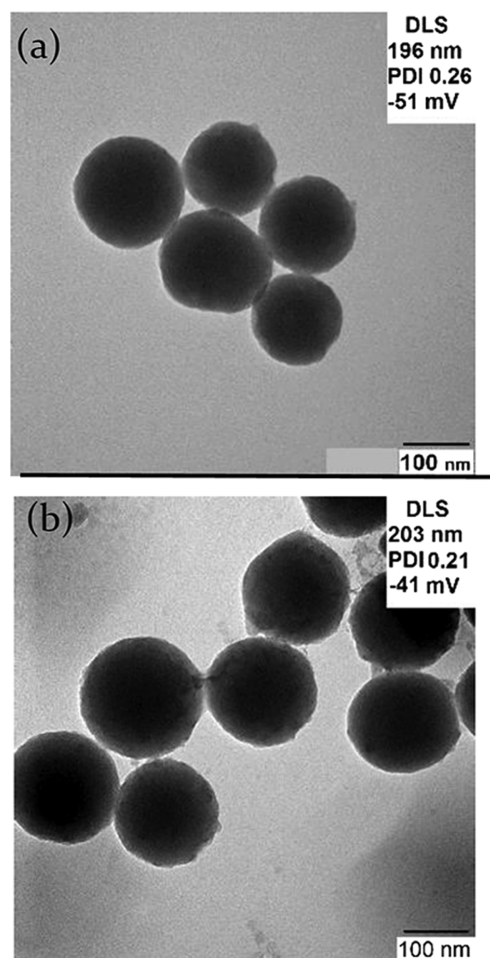

$\overline{100 \mathrm{~nm}}$

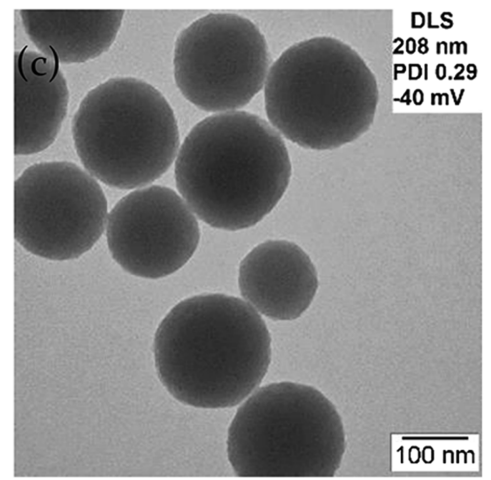

B
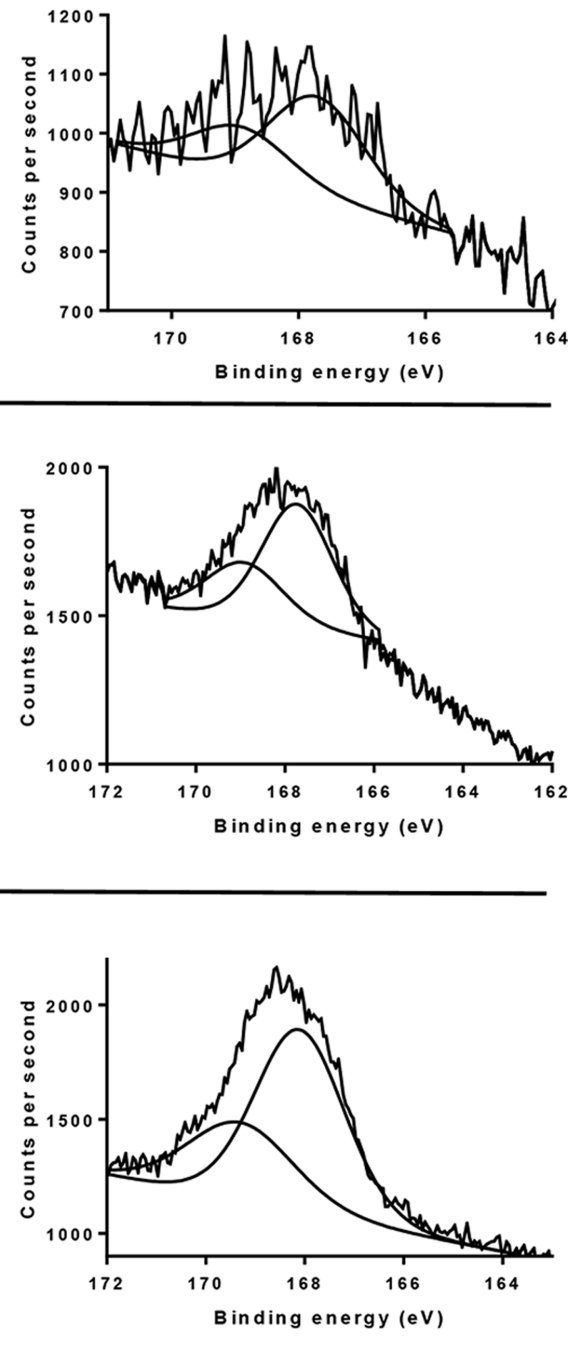

Figure 2. TEM images (A) and high-resolution S 2p XPS spectra (B) of spherical MSN-phenyl-SO 3 (3) with (a) DF 1.1 w/w \%; (b) DF 4.3 w/w \%; and (c) DF $11.7 \mathrm{w} / \mathrm{w} \%$. DLS measurements showing the hydrodynamic diameter, polydispersity index (PDI), and zeta potential in type II water are included. The scale bar represents $100 \mathrm{~nm}$.

the intermediate sulfonyl chloride (2). Thermogravimetric analysis (TGA) was used to measure the change in the weight of a sample of compound as it was heated to $900{ }^{\circ} \mathrm{C}$. The silica material undergoes insignificant weight loss with temperatures up to $900{ }^{\circ} \mathrm{C}$; hence, the weight loss recorded by TGA was attributed to the loss of the attached functional group and was used to estimate the DF in units of weight \%. The results indicated that MSN-phenyl- $\mathrm{SO}_{3}$ (3) systems with DFs of 11.7, 4.3 , and $1.1 \mathrm{w} / \mathrm{w} \%$ were successfully prepared (Figure S1A).

$\mathrm{X}$-ray photoelectron spectroscopy (XPS) was used to characterize the attached functional group of MSN-phenyl$\mathrm{SO}_{3}$ (3). The low-resolution XPS spectra confirmed the presence of key peaks such as $\mathrm{Si}, \mathrm{C}, \mathrm{S}$, and $\mathrm{Na}$ (Figure $\mathrm{S1B}$ ). The high-resolution peak of $S 2 p$ was observed at ca. $168 \mathrm{eV}$ for all three analogues of $\mathrm{MSN}$-phenyl-SO $\mathrm{S}_{3}$ (3) (Figure 2B), which signified the presence of the sulfonate form of sulfur. Moreover, ${ }^{13} \mathrm{C}$ solid-state NMR (SSNMR) of MSN-phenyl-SO ${ }_{3}$ (3) (DF $11.7 \mathrm{w} / \mathrm{w} \%)$ revealed key carbon peaks such as $\mathrm{C}-\mathrm{Si}$ and aromatic carbons, which confirmed the successful functionalization reaction (Figure $\mathrm{S} 1 \mathrm{C}$ ).

Propyl Thiol (4)- and Propyl Sulfonate (5)-Functionalized MSNs. MSNs were also functionalized with the propyl sulfonate group (MSN-propyl-SO $\mathrm{S}_{3}$ ) (5) by a two-step reaction involving the initial preparation of a propyl thiol intermediate (MSN-propyl-thiol) (4). MSN-propyl-thiol (4) (Figure 3A$\mathrm{A}(\mathrm{a}))$ ) had a spherical morphology with sizes similar to those of MSN-phenyl-SO $\mathrm{S}_{3}$ (3) (Figure 2A). The XPS spectra of MSN-propyl-thiol (4) revealed a peak at $163 \mathrm{eV}$ corresponding to the thiol group (Figure 3B(a)).

MSN-propyl-thiol (4) with a DF of $10.7 \mathrm{w} / \mathrm{w} \%$ was then oxidized to form MSN-propyl-SO $\mathrm{S}_{3}$ (5) with two different DFs, 2.4 and $5.0 \mathrm{w} / \mathrm{w} \%$ (Figure S2A), and the particle size and morphology were unchanged (Figure $3 A(b, c)$ ). This GAG mimetic was selected because the benzene group of MSNphenyl- $\mathrm{SO}_{3}$ (3) is replaced with an alkyl group, which can therefore be used to compare the impact of aromatic and 
A
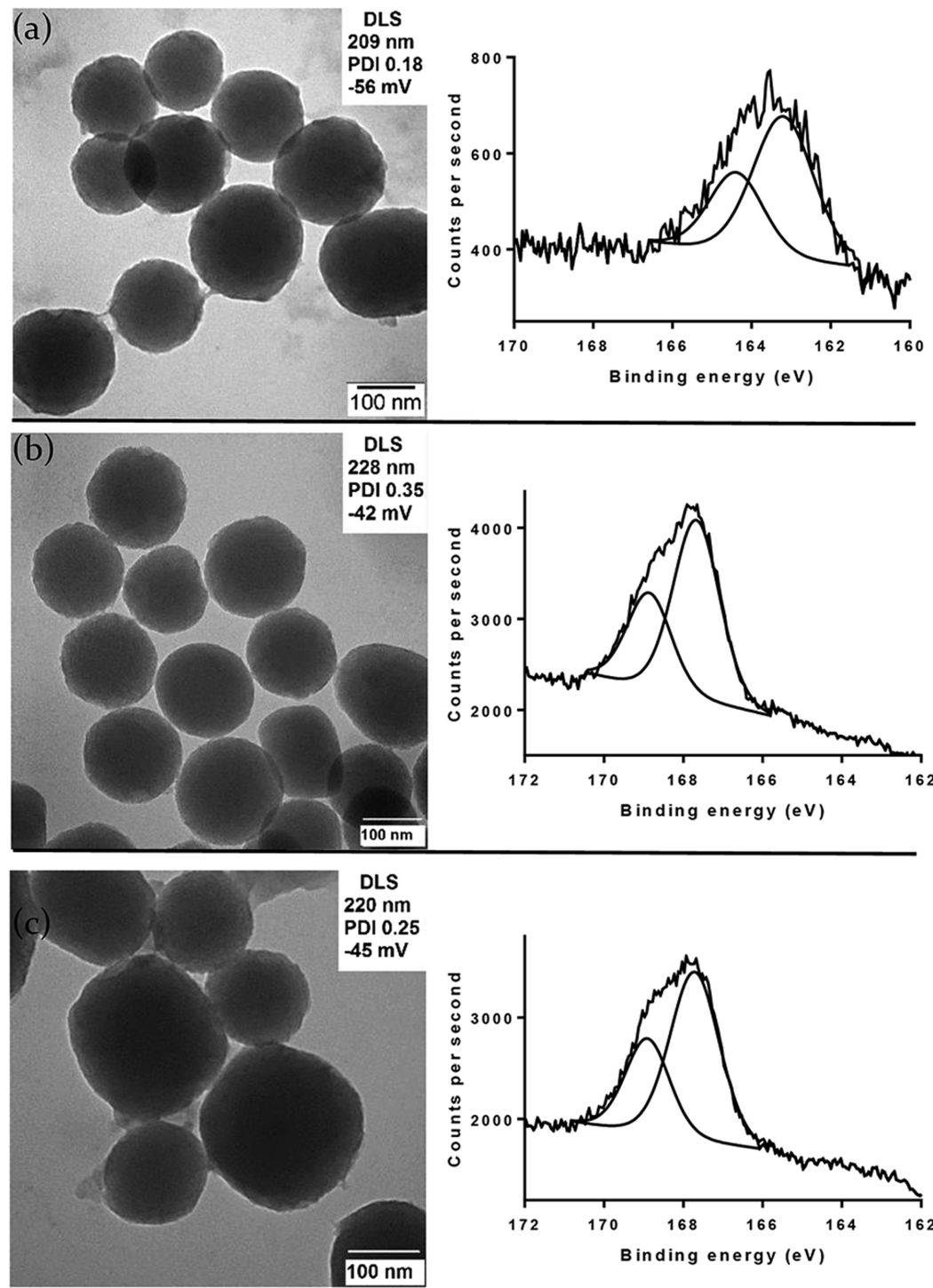

Figure 3. TEM images (A) and high-resolution S 2p XPS spectra (B) of spherical nanoparticles: (a) MSN-thiol (4) (DF $10.7 \mathrm{w} / \mathrm{w} \%$ ); (b) MSNpropyl- $\mathrm{SO}_{3}(5)$ (DF $2.4 \mathrm{w} / \mathrm{w} \%$ ); and (c) MSN-propyl-SO 3 (5) (DF $5.0 \mathrm{w} / \mathrm{w} \%$ ). DLS measurements determining the hydrodynamic diameter, PDI, and zeta potential in type II water are included. The scale bar represents $100 \mathrm{~nm}$.

hydrophobic interactions on antiviral activity. On the basis of the XPS spectra, the oxidation of thiol (4) to sulfonate (5) led to the shift of the $S 2 p$ peak from ca. $163 \mathrm{eV}$ (Figure 3B(a)) to $168 \mathrm{eV}$ (Figure $3 \mathrm{~B}(\mathrm{~b}, \mathrm{c})$ ), which is indicative of the complete conversion of the thiol groups to the sulfonate form. ${ }^{13} \mathrm{C}$ SSNMR spectra of MSN-propyl-SO $\mathrm{S}_{3}(5)$ with a DF of $5.0 \mathrm{w} / \mathrm{w}$ $\%$ revealed signals for aliphatic carbons, which is consistent with an aliphatic sulfonate (Figure S2C). Oxidation decreased the weight $\%$ of the functional group from 10.7 to 5.0 and $2.4 \mathrm{w} / \mathrm{w}$ $\%$ despite the higher molecular weight of the propyl sulfonate group (5), compared to the propyl thiol group (4). This indicates the possible detachment of organic groups from the surface of MSNs during the oxidation process, a phenomenon that was observed previously on oxidized silica surfaces. ${ }^{30}$

Zwitterionic Sulfonate-Functionalized MSNs (6). The anionic sulfonate group is believed to be critical for binding to the basic amino acid residues of HSV glycoproteins via electrostatic interactions. To investigate the effect of incorpo- rating a positively charged group alongside a sulfonate moiety, a zwitterionic compound comprising both quaternary ammonium and sulfonate groups was functionalized onto the MSNs. As illustrated in Figure S3A, the MSNs functionalized with the zwitterionic compound ( $\mathrm{MSN}-\mathrm{Zw}-\mathrm{SO}_{3}$ ) (6) had a size and morphology similar to those of the other functionalized nanoparticles (3-5). Despite the attachment of a zwitterionic functional group with a DF of $9.9 \mathrm{w} / \mathrm{w} \%$ (Figure S3B), the zeta potential was negatively charged, possibly because of the contribution of the negatively charged silanol groups (Figure $\mathrm{S} 3 \mathrm{~A}$ ). XPS detected the sulfonate group and nitrogen atom (Figure S3C,D), and the ${ }^{13} \mathrm{C}$ SSNMR spectrum (Figure S3E) was consistent with the structure of $\mathbf{6}$. However, the sodium counterion was not detected in the samples despite the presence of the sulfonate group and stirring the nanoparticles in aqueous $\mathrm{NaCl}$ solution $(10 \mathrm{w} / \mathrm{v} \%)$ twice for $2 \mathrm{~h}$. This suggests that the sulfonate group may form a stable intramolecular salt 
with the quaternary ammonium group, thus hindering the conversion of the sulfonate to the sodium salt.

Phenyl-Functionalized MSNs (7). A one-step procedure afforded MSNs functionalized with a hydrophobic phenyl group (MSN-phenyl) (7). Similar to the other compounds, MSN-phenyl (7) formed spherical particles of 100-150 nm in diameter, and DLS revealed PDI and zeta potential values similar to those of other types of functionalized particles (Figure S4A). The negative charge of MSN-phenyl (7) indicates that, similar to $\mathrm{MSN}-\mathrm{Zw}-\mathrm{SO}_{3}(6)$, the nanoparticles probably contain a substantial amount of silanol groups. Nonetheless, TGA revealed the successful attachment of the phenyl group to the MSN surface with an approximate weight loss (DF) of $6.8 \mathrm{w} / \mathrm{w} \%$ (Figure S4B). Furthermore, XPS showed strong intensity of the carbon peak without the appearance of other elemental peaks (Figure S4C). The highresolution C 1s spectra revealed a broad peak between 290 and $295 \mathrm{eV}$ corresponding to the aromatic carbons (Figure S4D). This was confirmed by the ${ }^{13} \mathrm{C}$ SSNMR spectra which identified aromatic carbons linked to the silica nanoparticles via a $\mathrm{Si}-\mathrm{C}$ bond (Figure S4E).

SARs of Functionalized MSNs. The antiviral activity of the functionalized MSNs toward HSV-1 and HSV-2 was evaluated using a plaque reduction assay. Plaques are visible disruptions of the cell monolayer formed following the infection of cells by viruses such as HSV. Hence, the effectiveness of an antiviral agent can be evaluated based on its ability to reduce the formation of plaques, quantified by the percent reduction of the plaque number relative to the untreated control (\% viral inhibition). Different concentrations of nanoparticles were used to test the antiviral activity of 3 and 5 against HSV-1 (208 $\mu \mathrm{g} / \mathrm{mL}$ nanoparticles) and HSV-2 (52 $\mu \mathrm{g} / \mathrm{mL}$ nanoparticles). These concentrations provided strong antiviral activity without causing complete (100\%) inhibition. If equal concentrations of nanoparticles were used to evaluate the activity against both HSV-1 and HSV-2, all analogues of MSNphenyl- $\mathrm{SO}_{3}$ (3) and $\mathrm{MSN}$-propyl- $\mathrm{SO}_{3}$ (5) may have shown extremely high viral inhibition of HSV-2 or extremely low inhibition of HSV-1, which would make comparisons of different nanoparticles difficult.

To study the antiviral activity, the functionalized nanoparticles were initially incubated with the viral suspension for 1 $\mathrm{h}$ before being inoculated to Vero cells. All analogues of MSNphenyl- $\mathrm{SO}_{3}$ (3) and $\mathrm{MSN}$-propyl- $\mathrm{SO}_{3}$ (5) displayed antiviral activity against HSV-1 and HSV-2 (Figure 4A,B). For both HSV-1 and HSV-2, the absolute antiviral response was greater for $\mathrm{MSN}$-phenyl-SO $\mathrm{SO}_{3}$ (3) than MSN-propyl-SO 3 (5). Furthermore, when the antiviral activities of $\mathrm{MSN}$-phenyl- $\mathrm{SO}_{3}$ (3) and $\mathrm{MSN}$-propyl-SO $\mathrm{SO}_{3}$ (5) of similar weight \% of attached functional group were compared; MSN-phenyl-SO $\mathrm{SO}_{3}$ (3) (DF $4.3 \mathrm{w} / \mathrm{w} \%)$ had a statistically greater antiviral effect against both HSV-1 and HSV-2 compared to MSN-propyl-SO $\mathrm{SO}_{3}$ (5) (DF $5.0 \mathrm{w} / \mathrm{w} \%)(p<0.05$; two-tailed paired $t$-test) $(3: 86 \%$ HSV-1 inhibition and 92\% HSV-2 inhibition and 5: 28\% HSV-1 inhibition and $34 \%$ HSV-2 inhibition). The two compounds had similar physical properties such as morphology, PDI, and zeta potential; hence, these results indicate that the benzene group of $\mathrm{MSN}$-phenyl- $\mathrm{SO}_{3}$ (3) enhances the antiviral activity in comparison to the propyl group of $\mathrm{MSN}-$ propyl- $\mathrm{SO}_{3}$ (5). Alternatively, if MSN-phenyl- $\mathrm{SO}_{3}$ (3) and MSN-propyl- $\mathrm{SO}_{3}$ (5) were to be compared based on the number of attached functional groups, instead of similar weight $\%$ of attached group, the difference in antiviral activity would probably be
H S V - 1

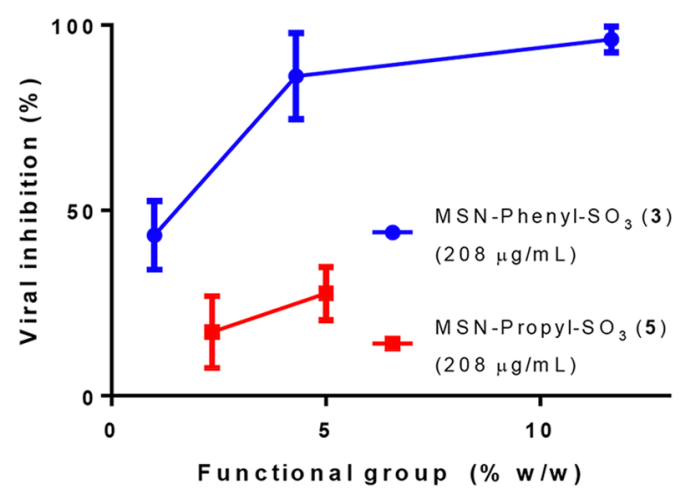

H S V - 2

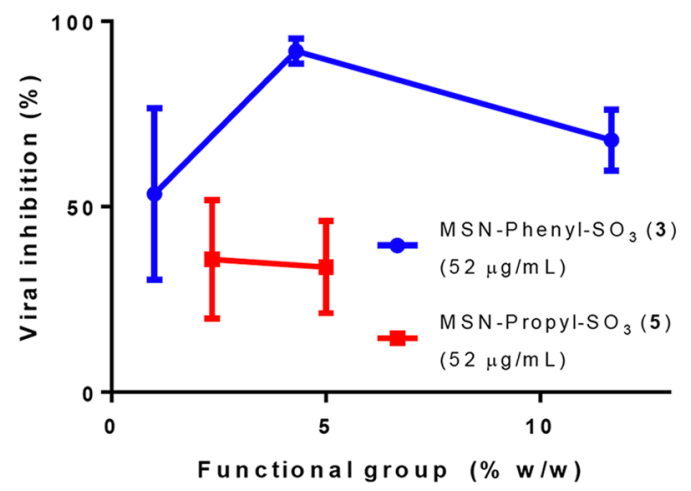

C

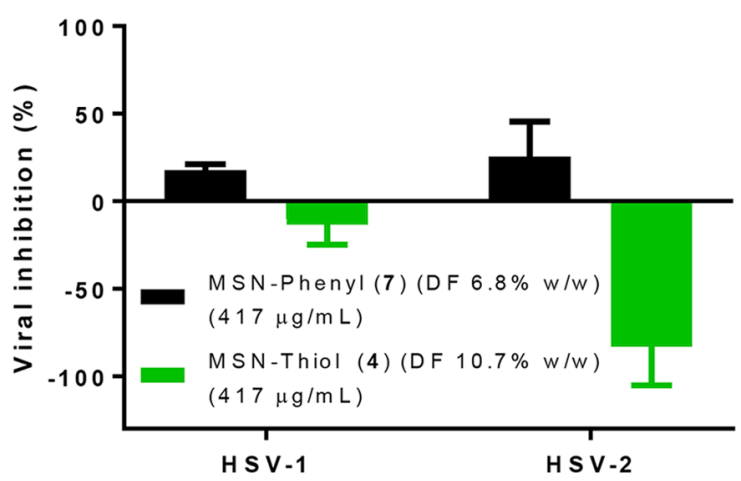

Figure 4. Antiviral activity of MSN-phenyl- $\mathrm{SO}_{3}$ (3) and MSN-propyl$\mathrm{SO}_{3}$ (5) of varying DFs on (A) HSV-1 (208 $\mu \mathrm{g} / \mathrm{mL}$ nanoparticles) and (B) HSV-2 (52 $\mu \mathrm{g} / \mathrm{mL}$ nanoparticles). (C) Antiviral activity of MSN-phenyl (7) (DF $6.8 \mathrm{w} / \mathrm{w} \%)(417 \mu \mathrm{g} / \mathrm{mL}$ nanoparticles) and MSN-propyl-thiol (4) (DF $10.7 \mathrm{w} / \mathrm{w} \%$ ) (417 $\mu \mathrm{g} / \mathrm{mL}$ nanoparticles) on HSV-1 and HSV-2. The antiviral activity was studied using a plaque reduction assay. Viral inhibition (\%) was determined by the percent reduction of plaque numbers compared to the untreated control. The values are the mean $\pm S D$ of three independent experiments with duplicate wells per treatment.

even greater because benzene sulfonate has a higher molecular weight than propyl sulfonate. The higher antiviral response against HSV observed for MSN-phenyl- $\mathrm{SO}_{3}$ (3) can be attributed to the greater hydrophobicity of 3 due to the presence of the phenyl group. Previous studies have demonstrated the importance of hydrophobic groups in relation to anti-HSV activity. Jenssen et al. demonstrated that introducing two hydrophobic residues into a cationic peptide 
increased its binding to the GAG, heparan sulfate, ${ }^{4}$ whereas Trybala et al. demonstrated that replacing either of the two hydrophobic amino acids with threonine in the peptide mimicking the binding site of $\mathrm{gC}$ substantially reduced the binding to heparan sulfate and infectivity. ${ }^{7}$ Dendrimers capped with the more hydrophobic naphthalene sulfonate groups were significantly more potent at inhibiting HSV-2 infection of human embryonic lung cells than dendrimers with phenyl sulfonate groups. ${ }^{8}$ Moreover, increasing the degree of sulfation also increased the activity. ${ }^{8}$

An apparent concentration-response relationship was established for MSN-phenyl- $\mathrm{SO}_{3}$ (3), with the maximal effect occurring for nanoparticles at a relatively low DF of $4.3 \mathrm{w} / \mathrm{w} \%$. However, increasing the DF of MSN-propyl- $\mathrm{SO}_{3}$ (5) from 2.4 to $5.0 \mathrm{w} / \mathrm{w} \%$ did not increase the antiviral effect $(p>0.05$; two-tailed $t$-test), based on the two densities that were studied. When the concentrations of MSN-propyl- $\mathrm{SO}_{3}$ (5) were doubled from 208 to $416 \mu \mathrm{g} / \mathrm{mL}$ for HSV-1 and from 52 to $104 \mu \mathrm{g} / \mathrm{mL}$ for HSV-2, although a higher antiviral activity was observed, the antiviral response again did not increase with the DF ( $p>0.05$; two-tailed $t$-test) (Figure S5). This suggests that the maximum antiviral activity of $\mathrm{MSN}$-propyl- $\mathrm{SO}_{3}$ (5) was achieved at a DF equal to or lower than $2.4 \mathrm{w} / \mathrm{w} \%$. This value is much lower than the density required to achieve a maximum response with $\mathrm{MSN}$-phenyl- $\mathrm{SO}_{3}$ (3). However, the absolute response of $\mathrm{MSN}$-phenyl- $\mathrm{SO}_{3}$ (3) was much greater than that of MSN-propyl-SO $\mathrm{S}_{3}$ (5) despite the response of MSN-propyl$\mathrm{SO}_{3}$ (5) reaching a plateau at a lower weight \% of functional group than that of $\mathrm{MSN}$-phenyl- $\mathrm{SO}_{3}$ (3).

Both MSN-phenyl-SO $\mathrm{S}_{3}$ (3) and $\mathrm{MSN}$-propyl- $\mathrm{SO}_{3}$ (5) displayed an antiviral activity, so to determine the effect of the sulfonate group on the activity, analogues that lacked this group were synthesized. In the case of MSN-phenyl- $\mathrm{SO}_{3}$ (3), a phenyl analogue (MSN-phenyl 7, DF $6.8 \mathrm{w} / \mathrm{w} \%)$ was made, and for MSN-propyl-SO 3 (5), a propyl thiol analogue (MSNpropyl-thiol 4, DF $10.7 \mathrm{w} / \mathrm{w} \%)$ was prepared. In the plaque reduction assay, a higher concentration of these functionalized nanoparticles was used in comparison to previous experiments (417 $\mu \mathrm{g} / \mathrm{mL} 4$ and 7 for both HSV-1 and HSV-2 compared with $208 \mu \mathrm{g} / \mathrm{mL}$ used for 3 and $\mathbf{5}$ previously) to give the compounds an ample opportunity to exert an antiviral effect. MSN-phenyl (7) displayed a weak antiviral activity toward both virus subtypes, whereas MSN-propyl-thiol (4) did not reduce the formation of plaques (Figure $4 \mathrm{C}$ ). Therefore, a sulfonate group (3 and 5), ${ }^{14-17}$ but not a thiol group (4), endows the nanoparticles with a strong antiviral activity, and an aryl sulfonate (3) is more active than an alkyl sulfonate (5) (Figure 4). Negative viral inhibition was observed for MSN-propyl-thiol (4), which means that the cells incubated with the compound had higher plaque numbers than the untreated control. The reason for this observation, which suggests an increase in the efficiency of virus attachment/absorption, is unknown. It may be speculated that MSN-thiol (4) may increase the local concentration of viruses at the cell membrane or alternatively affect the cell or viral membrane to promote fusion.

These results demonstrate the importance of the negatively charged sulfonate group for anti-HSV activity. Next, we investigated whether attaching a zwitterionic functional group, comprised of a cationic quaternary ammonium group and a sulfonate group, onto MSNs confers antiviral activity to MSN$\mathrm{Zw}-\mathrm{SO}_{3}$ (6). $\mathrm{MSN}-\mathrm{Zw}-\mathrm{SO}_{3}$ (6) (DF $9.9 \mathrm{w} / \mathrm{w} \%$ ) was unable to exert antiviral activity on $\mathrm{HSV}-1$ and $\mathrm{HSV}-2$, even at concentrations two-fold greater than the concentrations used to previously study MSN-phenyl-SO $\mathrm{SO}_{3}$ (3) and MSN-propyl$\mathrm{SO}_{3}(5)$ (Figure 5). As described above, the sulfonate group of $\mathrm{MSN}-\mathrm{Zw}-\mathrm{SO}_{3}$ (6) may form an intramolecular ionic bond with the quaternary ammonium group, thus diminishing the antiviral response.

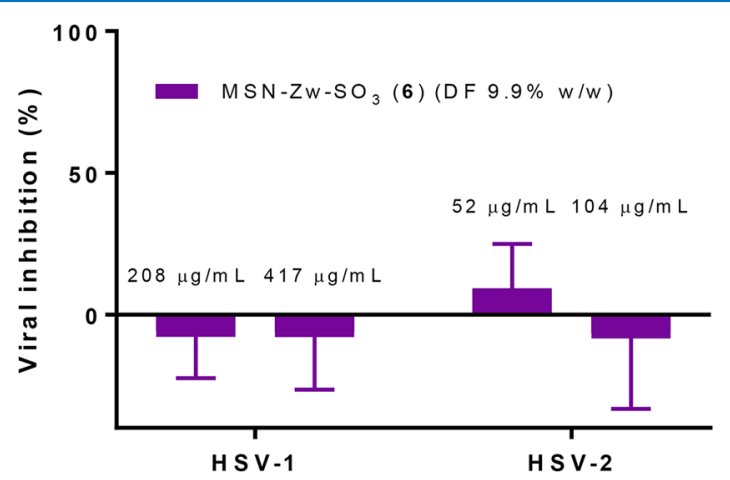

Figure 5. Antiviral activity of $\mathrm{MSN}-\mathrm{Zw}-\mathrm{SO}_{3}$ (6) (DF $9.9 \mathrm{w} / \mathrm{w} \%$ ) against HSV-1 (208 and $417 \mu \mathrm{g} / \mathrm{mL}$ nanoparticles) and HSV-2 (52 and $104 \mu \mathrm{g} / \mathrm{mL}$ nanoparticles) using a plaque reduction assay. Viral inhibition (\%) was determined by the percent reduction of plaque numbers compared to the untreated control. The values are the mean $\pm \mathrm{SD}$ of three independent experiments with duplicate wells per treatment.

In accordance with our previous results, ${ }^{17}$ unfunctionalized MSNs (1) did not reduce the formation of plaques of both HSV-1 and HSV-2 (Figure S6). Therefore, the antiviral activity of nanoparticles observed in this study can be attributed to the action of the attached functional groups, with an aryl sulfonate (3) being optimal for antiviral activity amongst the series of tested compounds (3-7).

Our previous study ${ }^{17}$ and related studies ${ }^{14-16}$ determined that aryl and alkyl sulfonate groups attached to nanoparticles have low toxicity to cells. Forming MSNs is also likely to reduce the toxicity relative to solid silica nanoparticles because of the decreased number of outer surface silanol groups. ${ }^{17,31}$ The nanoparticles are unlikely to have interfered with the plaque reduction assays because the concentrations $(52-417 \mu \mathrm{g} / \mathrm{mL})$ and cell incubation time $(2 \mathrm{~h})$ were much lower than those in the conditions used to undertake cell toxicity studies $(1000 \mu \mathrm{g} /$ $\mathrm{mL}$ and $48 \mathrm{~h}) .{ }^{17}$

Preparation of GAG Mimetic-Functionalized MSNs Loaded with Acyclovir. Nanoparticles functionalized with GAG mimetics prevent HSV infection by inhibiting viral entry. ${ }^{14-17}$ In addition to providing a stable scaffold for surface functionalization, a unique property of MSNs is that their pores can be loaded with large amounts of $\operatorname{drug}(\mathrm{s})$, which widens the therapeutic scope of MSNs. ${ }^{18}$ In this study, we prepared MSNs functionalized with sodium benzene sulfonate and loaded with acyclovir, which is a first-line drug for HSV infection. This created multifunctional MSNs, which in principle could inhibit HSV infection in two ways: (1) extracellularly, via inhibition of viral entry by the GAG mimetic, and (2) intracellularly, via the inhibition of viral DNA replication by acyclovir (Figure 1 ).

Functionalizing MSNs with high densities of functional groups can cause narrowing of pore openings and impede drug loading. ${ }^{32}$ Hence, MSN-phenyl-SO ${ }_{3}$ (3) (DF $6.9 \mathrm{w} / \mathrm{w} \%$ ) (Figure 6A) was chosen for loading with acyclovir because, according to earlier results, this would afford strong inhibition of viral entry (Figure 4A), whilst a relatively low DF of phenyl$\mathrm{SO}_{3}$ (3) (DF $6.9 \mathrm{w} / \mathrm{w} \%$ ) was predicted to be less likely to 
A

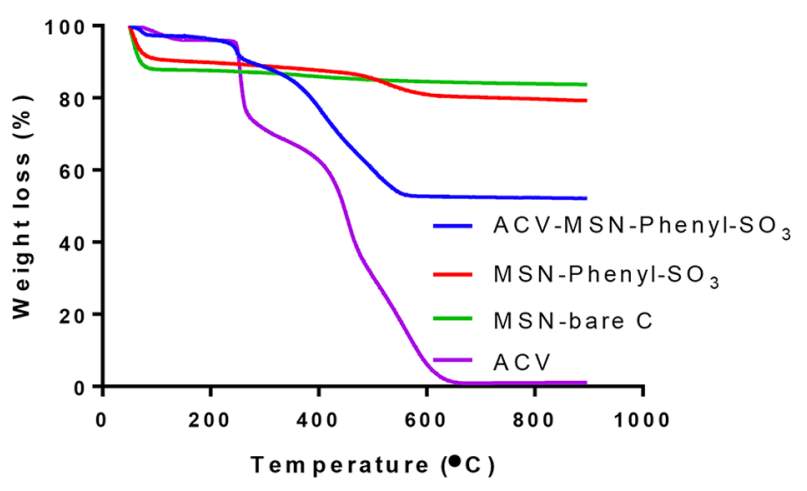

B

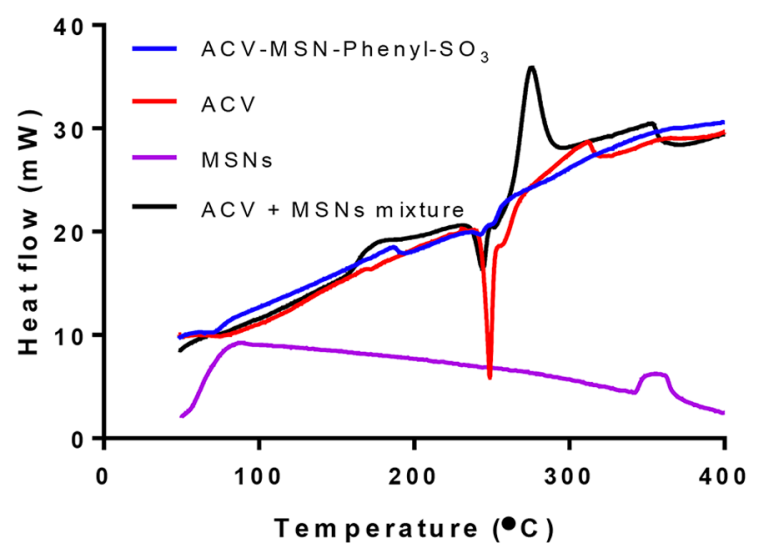

Figure 6. (A) TGA graph showing the weight loss of ACV-MSNphenyl- $\mathrm{SO}_{3}$ and $\mathrm{MSN}$-phenyl- $\mathrm{SO}_{3}$ with increasing temperature $\left({ }^{\circ} \mathrm{C}\right)$. The difference in weight loss represents the amount of loaded acyclovir. Weight loss (\%) of samples was measured starting from 150 ${ }^{\circ} \mathrm{C}$ to exclude the weight loss due to the evaporation of water (range studied: $150-900{ }^{\circ} \mathrm{C}$ ). (B) DSC curves of ACV-MSN-phenyl-SO ${ }_{3}$, free ACV, unfunctionalized MSNs (1), and a physical mixture of ACV and unfunctionalized MSNs. The presence or lack of a peak at the melting point of acyclovir $\left(\mathrm{ca} .250{ }^{\circ} \mathrm{C}\right)$ indicates whether the drug is in the crystalline or amorphous state.

impede drug loading. To load acyclovir, MSN-phenyl- $\mathrm{SO}_{3}$ (3) was first stirred in a concentrated solution of acyclovir in type II pure water for $48 \mathrm{~h}$ to allow acyclovir to deposit inside the mesopores of MSN-phenyl- $\mathrm{SO}_{3}$. The solvent was then evaporated in vacuo to encourage further deposition of the drug into the mesopores, resulting in the formation of $\mathrm{ACV}$ MSN-phenyl- $\mathrm{SO}_{3}$. TGA revealed a high drug loading of 34.0 $\mathrm{w} / \mathrm{w} \%$ (Figure 6A). Free acyclovir, and acyclovir physically mixed with MSNs, displayed a sharp melting point at ca. 250 ${ }^{\circ} \mathrm{C}$ in the DSC curve, which signified the crystalline state of acyclovir (Figure 6B). Following drug loading to form ACV$\mathrm{MSN}$-phenyl- $\mathrm{SO}_{3}$, the melting point peak disappeared, indicating the transition of acyclovir to the amorphous state and the successful incorporation of the drug within the mesopores. Moreover, XPS revealed that ACV-MSN-phenyl$\mathrm{SO}_{3}$ had a sharp nitrogen peak (Figure $\mathrm{S} 7 \mathrm{~A}$ ), which signified the presence of acyclovir while retaining the sulfonate group (Figure S7B). As a control, unfunctionalized MSNs (1) were also successfully loaded with acyclovir (ACV-MSN) with a final drug loading value of $30.0 \mathrm{w} / \mathrm{w} \%$ (Figure S8).
Drug Release and Antiviral Assay of ACV-MSNPhenyl- $\mathrm{SO}_{3}$. A drug release experiment was conducted to determine the rate and extent of acyclovir release from the ACV-MSN and ACV-MSN-phenyl-SO ${ }_{3}$ (Figure 7A). This was

A

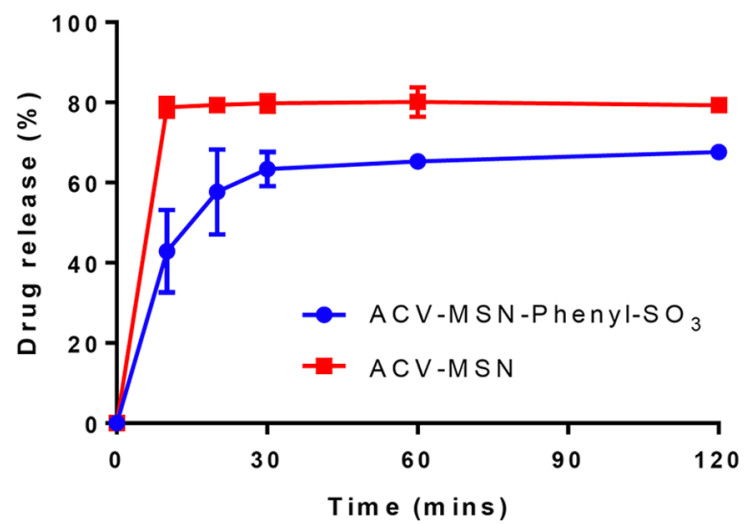

B

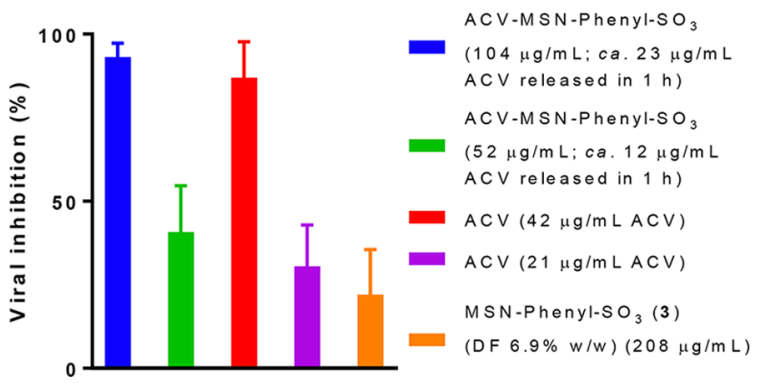

Figure 7. (A) Drug release experiment was conducted for ACV-MSNphenyl-SO $\mathrm{S}_{3}$ and ACV-MSN in a phosphate buffer solution with a $\mathrm{pH}$ of 7.4. Drug release \% was determined by the absorbance intensity at a $\lambda_{\max }$ value of $253 \mathrm{~nm}$ measured by UV-visible spectrophotometry. The values are the mean \pm SD of two independent experiments. (B) Results of a plaque reduction assay whereby the cells were treated with ACV-MSN-phenyl-SO ${ }_{3}$ following the entry of HSV-1 to Vero cells. Viral inhibition (\%) was determined by the percent reduction of plaque numbers compared to the untreated control. The values are the mean \pm SD of three independent experiments with duplicate wells per treatment.

done to help interpret the antiviral activity of the loaded particles in subsequent plaque reduction assays. In the case of ACV-MSN, the release profile reached a plateau within $10 \mathrm{~min}$, showing the release of ca. $79 \%$ of total acyclovir. With no physical barrier to impede drug release, the burst release behavior of acyclovir from ACV-MSN was expected. Meanwhile, the release of acyclovir from ACV-MSN-phenyl- $\mathrm{SO}_{3}$ was more gradual, reaching a plateau at ca. $30 \mathrm{~min}$, and the extent of acyclovir release was less, with ca. $70 \mathrm{w} / \mathrm{w} \%$ release after $24 \mathrm{~h}$ (Figure S9). This may be due to the effect of the surface functional groups, which may narrow the pore opening, reducing the rate of drug release, and interact with the drug, preventing complete drug release. Incomplete drug release from MSNs has been reported in the literature, ${ }^{33-35}$ and future studies should aim to ensure that release of acyclovir from ACV-MSN-phenyl- $\mathrm{SO}_{3}$ is more prolonged and complete. Sealing the pores with materials such as polymers or functionalizing inner porous surfaces with small hydrophobic molecules may be useful ways of controlling drug release. 
The potential multifunctional antiviral effects of the ACV$\mathrm{MSN}$-phenyl- $\mathrm{SO}_{3}$ system were investigated by treating Vero cells with the nanoparticles at two different stages of the viral infectious life cycle-preinfection and postinfection. To evaluate the efficacy of ACV-MSN-phenyl- $\mathrm{SO}_{3}$ postviral entry, cells were initially infected with HSV-1, and extracellular virions were removed by washing with phosphate-buffered saline (PBS) to ensure that any observed antiviral effect is primarily due to the activity of acyclovir rather than the GAG mimetics. ACV-MSN-phenyl-SO $\mathrm{S}_{3}$ at nanoparticle concentrations of 52 and $104 \mu \mathrm{g} / \mathrm{mL}$ was then incubated with cells for $1 \mathrm{~h}$. Figure $7 \mathrm{~B}$ illustrates that ACV-MSN-phenyl- $\mathrm{SO}_{3}$ and free acyclovir at their highest tested concentrations completely inhibited infection when the cells were treated postviral entry. Moreover, MSN-phenyl-SO $\mathrm{S}_{3}$ (3) without loaded acyclovir (MSN-phenyl$\mathrm{SO}_{3}, \mathrm{DF} 6.9 \mathrm{w} / \mathrm{w} \%$ ) at a particle concentration of $208 \mu \mathrm{g} / \mathrm{mL}$ exerted a relatively weak antiviral effect against HSV-1. Therefore, the results indicate that the observed antiviral effect is primarily due to the action of acyclovir and not due to the effect of the GAG mimetic.

On the basis of the drug release study, ca. $65 \%$ of acyclovir is released from ACV-MSN-phenyl- $\mathrm{SO}_{3}$ at $\mathrm{pH}$ 7.4, following a $1 \mathrm{~h}$ incubation period (Figure 7A). Therefore, ACV-MSN-phenyl$\mathrm{SO}_{3}$ at concentrations of 52 and $104 \mu \mathrm{g} / \mathrm{mL}$ with $34 \mathrm{w} / \mathrm{w} \%$ drug loading would release ca. 12 and $23 \mu \mathrm{g} / \mathrm{mL}$ acyclovir, respectively, during the postinfection plaque reduction assay discussed above. To determine if the acyclovir released from ACV-MSN-phenyl- $\mathrm{SO}_{3}$ retains its antiviral potency, comparison was made with free acyclovir at concentrations of ca. 21 and $42 \mu \mathrm{g} / \mathrm{mL}$. ACV-MSN-phenyl- $\mathrm{SO}_{3}$ gave an antiviral effect similar to that of a higher equivalent concentration of free acyclovir (Figure 7B), which indicates that the processes used to prepare ACV-MSN-phenyl- $\mathrm{SO}_{3}$ do not diminish the antiviral potency of acyclovir. Moreover, the antiviral activity of acyclovir loaded into ACV-MSN-phenyl- $\mathrm{SO}_{3}$ appears to be greater than that of free acyclovir, possibly because of the improved delivery of acyclovir to infected cells via cellular uptake of nanoparticles as described by Cavalli et al. ${ }^{27}$

The effect of the attached GAG mimetic of ACV-MSNphenyl- $\mathrm{SO}_{3}$ was evaluated to confirm the retention of its antiviral activity, which would endow the antiviral system with dual functionality. Following the incubation of HSV-1 with ACV-MSN-phenyl-SO $\mathrm{S}_{3}$, including ACV-MSN and free acyclovir as controls, the mixture was inoculated to cells for $1 \mathrm{~h}$. The cells were then washed with PBS to minimize the exposure of the cells to acyclovir during the subsequent incubation period, thus ensuring that the observed antiviral effect is primarily due to the GAG mimetic rather than acyclovir. Although the cells were initially exposed to acyclovir for $1 \mathrm{~h}$, this was before virus infection, which means that sufficient amounts of viral thymidine kinase are unlikely to be present, leading to low concentrations of activated acyclovir. This concept is supported by the lack of antiviral effect of free acyclovir (Figure 8) at concentrations that gave close to $100 \%$ antiviral activity in the postinfection assay (Figure $7 \mathrm{~B}$ ). Furthermore, the ACV-MSN would release ca. $200 \mu \mathrm{g} / \mathrm{mL}$ acyclovir based on the results of the drug release assay (Figure $7 \mathrm{~A}$ ), and it too exhibited no antiviral activity (Figure 8). Importantly, ACV-MSN-phenyl$\mathrm{SO}_{3}$ inhibited the viral infection of cells, which is consistent with the inhibition of viral entry. It is postulated that the attached GAG mimetic of ACV-MSN-phenyl- $\mathrm{SO}_{3}$ bound the majority of virions during the initial incubation period to make the virus ineffective. When inoculated to Vero cells, the virions

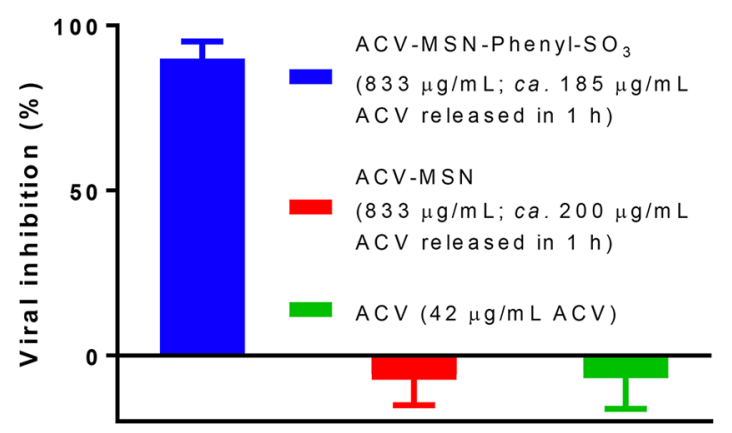

Figure 8. Results of a plaque reduction assay whereby the cells were treated with nanoparticles (ACV-MSN-phenyl-SO ${ }_{3}$ and ACV-MSN) and acyclovir previral entry of HSV-1. Viral inhibition (\%) was determined by the percent reduction of plaque numbers compared to the untreated control. The values are the mean $\pm \mathrm{SD}$ of three independent experiments with duplicate wells per treatment.

bound to ACV-MSN-phenyl-SO $\mathrm{S}_{3}$ would be unable to enter and infect cells, leading to minimal plaque growth. Both ACV-MSN and free acyclovir are unable to bind to virions, and hence following inoculation to Vero cells, the unbound HSV-1 is free to interact with cell receptors and infect cells. A similar result was observed in a study by Nazemi et al., where the outer surface of polymersomes was attached with sialic acid to inhibit viral entry of influenza virus and loaded with zanamivir to prevent the release of newly formed viruses from the host cell. ${ }^{36}$ Park et al. combined a cationic peptide that is able to inhibit the viral entry of HSV-1 with acyclovir to also target two mechanisms. ${ }^{37}$ Such approaches may improve the antiviral effect, and further studies are warranted. Similarly, our proof-ofconcept study demonstrates the successful preparation of drugloaded GAG mimetic-functionalized nanoparticles which are able to target two viral infection pathways. Apart from small differences in viral entry glycoproteins, HSV-1 and HSV-2 are closely related. ${ }^{38}$ Therefore, ACV-MSN-phenyl- $\mathrm{SO}_{3}$ would likely produce a similar result when tested against HSV-2.

\section{CONCLUSIONS}

This study revealed the important SARs of GAG-mimetic functional groups attached to MSNs in terms of anti-HSV activity. The sulfonate group (3 and 5) was identified as a prerequisite in relation to antiviral activity, with the benzene group (3) enhancing the antiviral response in comparison to an alkyl group (5). MSNs with a benzene surface but lacking the sulfonate group (7) displayed a relatively weak antiviral activity, which highlights the importance of the sulfonate group. This study also demonstrated, for the first time, the inhibition of two different stages of the HSV life cycle by drug-loaded MSNs functionalized with GAG mimetics: inhibition of viral entry and inhibition of viral DNA replication. This proof-of-concept investigation will aid the development of more sophisticated drug delivery systems that are able to incorporate properties such as mucopenetration and/or sustained drug release. A greater antiviral effect of acyclovir was observed when loaded into ACV-MSN-SO $\mathrm{S}_{3}$ compared with free acyclovir; hence, the possibility of intracellular acyclovir release should be investigated in future studies.

\section{EXPERIMENTAL SECTION}

Materials and Reagents. Hydrogen peroxide $30 \mathrm{w} / \mathrm{w} \%$ was obtained from Chem-Supply. Ethanol, methanol, and toluene were purchased from Merck. Dry toluene was prepared 
by storing toluene over $3 \AA$ molecular sieves overnight. TEOS, CTAB, Pluronic F127, trimethoxyphenylsilane, 3-mercaptopropyltrimethoxysilane, and 1,3-propane sultone were purchased from Sigma-Aldrich. CSPTMS in dichloromethane $(50 \mathrm{w} / \mathrm{w} \%)$ was obtained from Acros Organics. (N,N-Dimethyl-3aminopropyl)trimethoxysilane was obtained from Gelest. PBS tablets purchased from AMRESCO were dissolved in water to obtain PBS pH 7.4 containing $137 \mathrm{mM}$ sodium chloride, 2.7 $\mathrm{mM}$ potassium chloride, and $10 \mathrm{mM}$ phosphate buffer. Dulbecco's modified Eagle medium (DMEM) was obtained from Invitrogen and was supplemented with penicillin, Lglutamine, and either 2 or $10 \mathrm{v} / \mathrm{v} \%$ fetal calf serum (FCS). The HSV-1 used was the HSV-1 H129-GFP strain described in McGovern et al. ${ }^{39}$ HSV-2 was a clinical isolate. Acyclovir was purchased from TCI. Unless stated otherwise, the experiments were conducted at room temperature $\left(\mathrm{ca} .23^{\circ} \mathrm{C}\right)$. The water used in this study was type II pure water according to ASTM specification D1193-06.

Synthesis of MSNs (1). CTAB (1.0 g) and Pluronic F127 $(4.0 \mathrm{~g})$ were stirred in ethanol and $\mathrm{NH}_{4} \mathrm{OH}\left(2.8 \% \mathrm{NH}_{3} \mathrm{w} / \mathrm{w}\right)$ $(2: 5 \mathrm{v} / \mathrm{v}, 298 \mathrm{~mL}$ total $)$ for $1 \mathrm{~h}$ to allow complete dissolution. Then, $3.6 \mathrm{~g}$ of TEOS was added to the solution, and the reaction mixture was stirred for $60 \mathrm{~s}$ and kept under quiescent conditions for $24 \mathrm{~h}$. The particles (1) were collected by centrifugation at a 28174 relative centrifugal force (rcf) for 15 min and washed twice with type II pure water and finally with ethanol. The particles (1) were dried in an oven overnight at 60 ${ }^{\circ} \mathrm{C}$.

Synthesis of MSN-Phenyl-SO 3 (3). MSNs (1) were functionalized with sodium benzene sulfonate to form MSNphenyl- $\mathrm{SO}_{3}$ (3) using a method based on our previously published procedure. ${ }^{17}$ Briefly, the sulfonyl chloride intermediate (2) was formed by stirring MSNs (1) in dry toluene (ca. 1:100 w/v ratio) and CSPTMS under reflux for $18-20 \mathrm{~h}$ under an atmosphere of nitrogen gas. Compound $\mathbf{2}$ was collected by centrifugation at an $18031 \mathrm{rcf}$ for $10 \mathrm{~min}$ and washed sequentially with toluene, ethanol, and acetone. To form sodium benzene sulfonate-functionalized MSNs (3), the sulfonyl chloride intermediate (2) was hydrolyzed by stirring in type II pure water for $24 \mathrm{~h}$, and then the particles were stirred in an aqueous solution of $\mathrm{NaCl} 10 \mathrm{w} / \mathrm{v} \%$ for $2 \mathrm{~h}$ twice. Excess $\mathrm{NaCl}$ was removed by washing the particles in type II pure water twice. The compound was dried in an oven overnight at $60{ }^{\circ} \mathrm{C}$. To synthesize batches of 3 with a lower density of benzene sulfonate groups, the DF of $\mathbf{2}$ was decreased by adding a smaller volume of CSPTMS in the functionalization reaction, which following hydrolysis produced 3 with a lower functionalization density. CSPTMS at volumes of 100, 150, and $250 \mu \mathrm{L}$ was added to ca. 450,270 , and $270 \mathrm{mg}$ of silica suspended in toluene, respectively, to form three batches of compound 2, which were then hydrolyzed to afford compound 3 with three different DFs.

Synthesis of MSN-Propyl-Thiol (4) and MSN-Propyl$\mathrm{SO}_{3}$ (5). To form the thiol intermediate, 3-mercaptopropyltrimethoxysilane was added dropwise to a suspension of MSNs (1) in methanol at $60{ }^{\circ} \mathrm{C}$ and stirred overnight. The particles were collected by centrifugation at a $32055 \mathrm{rcf}$ for $15 \mathrm{~min}$ and washed twice with type II pure water. The thiol-functionalized MSNs (MSN-propyl-thiol) (4) were dried in an oven overnight at $60{ }^{\circ} \mathrm{C}$.

To form propyl sulfonate-functionalized MSNs (MSNpropyl- $\mathrm{SO}_{3}$ ) (5), MSN-propyl-thiol (4) was oxidized by stirring in aqueous $\mathrm{H}_{2} \mathrm{O}_{2} 30 \mathrm{w} / \mathrm{w} \%$ for $24 \mathrm{~h}$. The particles were collected by centrifugation at an $18031 \mathrm{rcf}$ for $15 \mathrm{~min}$ and washed twice with type II pure water. The particles were stirred in an aqueous solution of $\mathrm{NaCl} 10 \mathrm{w} / \mathrm{v} \%$ for $2 \mathrm{~h}$ twice. Excess $\mathrm{NaCl}$ was removed by washing the particles in type II pure water twice. The compound was dried in an oven overnight at $60{ }^{\circ} \mathrm{C}$.

Synthesis of MSN-Zw-SO 3 (6). The protocol to synthesize 3-(dimethyl(3-(trimethoxysilyl)propyl)-ammonio)propane-1sulfonate was adapted from Estephan et al. ${ }^{40}$ 1,3-Propane sultone $(1.6 \mathrm{~mL})$ was added to a stirred solution of $N, N$ dimethyl-3-aminopropyl trimethoxysilane $(4 \mathrm{~mL})$ in $20 \mathrm{~mL}$ of acetone. The reaction mixture was stirred for $6 \mathrm{~h}$ under an atmosphere of nitrogen gas. The white precipitate was collected by centrifugation (18031 rcf, $5 \mathrm{~min}$ ) and washed twice with acetone. The compound was dried overnight in vacuo.

To functionalize zwitterionic silane onto the surface of silica nanoparticles (MSN-Zw-SO ${ }_{3}$ ) (6), a protocol adapted from Estephan et al. was used. ${ }^{40}$ MSNs (1) (140 mg) were dispersed in $30 \mathrm{~mL}$ of type II pure water, and an aqueous solution of 3(dimethyl(3-(trimethoxysilyl)propyl)-ammonio)propane-1-sulfonate $(0.5 \mathrm{~mL}$, ca. $160 \mathrm{mg} / \mathrm{mL}$ in type II pure water) was added. The mixture was stirred at $80{ }^{\circ} \mathrm{C}$ for $24 \mathrm{~h}$. The particles were collected by centrifugation ( $32055 \mathrm{rcf}, 15 \mathrm{~min}$ ) and washed twice with type II pure water. The particles were then stirred in aqueous $\mathrm{NaCl}$ solution $(10 \mathrm{w} / \mathrm{v} \%)$ twice for $2 \mathrm{~h}$. The compound (6) was finally washed with type II pure water and dried overnight at $60{ }^{\circ} \mathrm{C}$.

Synthesis of MSN-Phenyl (7). Trimethoxyphenylsilane (1.2 mL) was added to a stirred suspension of MSNs (1) (170 $\mathrm{mg}$ ) in $30 \mathrm{~mL}$ of dry toluene. The reaction proceeded under reflux for $20 \mathrm{~h}$ under an atmosphere of nitrogen gas. The particles were collected by centrifugation at an $18031 \mathrm{rcf}$ for 15 min and washed sequentially with toluene, ethanol, and acetone. The compound (MSN-phenyl) (7) was dried in an oven overnight at $60{ }^{\circ} \mathrm{C}$.

Preparation of Acyclovir-Loaded MSNs. MSN-phenyl$\mathrm{SO}_{3}$ (3) or unfunctionalized MSNs (1) (20 mg) were dispersed in $1 \mathrm{~mL}$ of ethanol using a bath sonicator for $10 \mathrm{~min}$ and then added to an aqueous solution of acyclovir $(50 \mathrm{mg}$ of acyclovir in $6 \mathrm{~mL}$ of type I pure water) and stirred at $200 \mathrm{rpm}$ for $48 \mathrm{~h}$. The solvent was removed in vacuo using a rotary evaporator, and the dried powder was washed six times with $10 \mathrm{~mL}$ of type II pure water to remove excess acyclovir adsorbed on the surface of drug-loaded nanoparticles. The compounds (ACV$\mathrm{MSN}$-phenyl- $\mathrm{SO}_{3}$ and ACV-MSN) were dried in an oven overnight at $60^{\circ} \mathrm{C}$.

Characterization. The hydrodynamic diameter, PDI, and zeta potential of the nanoparticle suspensions in type II pure water were measured using a Malvern Nano ZS Zetasizer. The size and morphology of the nanoparticles were determined based on TEM images using a JEOL 1010 instrument operated at $100 \mathrm{kV}$. The TEM samples were prepared on 200-mesh copper-coated grids.

A Mettler Toledo TGA/DSC 2 STAR system was used to obtain TGA data on the nanoparticles which were weighed into aluminum oxide crucibles. The weight loss of samples was recorded as the temperature was increased from $50-900{ }^{\circ} \mathrm{C}$ at a heating rate of $5{ }^{\circ} \mathrm{C} / \mathrm{min}$.

XPS was conducted using a Kratos Axis ULTRA X-ray photoelectron spectrometer. ${ }^{13} \mathrm{C}$ SSNMR spectra were obtained using a Bruker AVANCE III spectrometer operated at $300 \mathrm{MHz}$. 
Drug Release. The release of acyclovir from acyclovirloaded MSN-phenyl- $\mathrm{SO}_{3}$ was investigated using a $\mathrm{pH} 7.4$ phosphate buffer. ACV-MSN-phenyl-SO $\mathrm{S}_{3}$ or ACV-MSN was added to $50 \mathrm{~mL}$ of $\mathrm{pH} 7.4$ buffer and stirred at $100 \mathrm{rpm}$ at 37 ${ }^{\circ} \mathrm{C}$ under sink conditions. Samples $(1.5 \mathrm{~mL})$ were withdrawn at predetermined time intervals $(0,10,20,30 \mathrm{~min}, 1$, and $2 \mathrm{~h})$ and immediately replaced with an equal volume of fresh buffer solution to maintain a constant volume. The withdrawn samples were centrifuged (12000 rcf, $4 \mathrm{~min}$ ), and the concentration of acyclovir was determined using UV-visible spectrophotometry at a $\lambda_{\max }$ value of $253 \mathrm{~nm}$ by reference to a calibration curve $\left(R^{2}\right.$ values $\left.>0.99\right)$.

SAR Studies. Vero cells were grown overnight in 24-well plates at a seeding density of $1.2 \times 10^{5}$ cells/well. Nanoparticles suspended in PBS $(250 \mu \mathrm{L})$ were mixed with HSV-1 (ca. 49 plaque-forming units-pfu) or HSV-2 (ca. 38 pfu) diluted with DMEM 2\% FCS $(50 \mu \mathrm{L})$ and incubated for $1 \mathrm{~h}$. The suspension was inoculated to Vero cells, incubated for $1 \mathrm{~h}$ at 37 ${ }^{\circ} \mathrm{C}$ to enable virus binding/entry, and the suspension was then aspirated and overlayed with $0.6 \%$ carboxymethyl cellulose (CMC) in DMEM 2\% FCS at $1 \mathrm{~mL} /$ well. After incubating the plates for 3 days, the cells were fixed with formaldehyde in PBS $(0.4 \mathrm{w} / \mathrm{v} \%)$ and stained with toluidine blue in water $(0.1 \mathrm{w} / \mathrm{v}$ $\%)$, and the plaques were counted under a microscope. In our previous study, ${ }^{17} \mathrm{MSN}$-phenyl-SO 3 (3) was determined to have only minor effect on the viability of Vero cells following $48 \mathrm{~h}$ of incubation at concentrations up to $1000 \mu \mathrm{g} / \mathrm{mL}$. Therefore, cytotoxicity was not studied in this project because, in the SAR studies, relatively low concentrations of nanoparticles were used with relatively short exposure times.

Acyclovir Study. Preinfection-Vero cells were grown overnight in 24-well plates at a seeding density of $1.2 \times 10^{5}$ cells/well. ACV-MSN-phenyl-SO ${ }_{3}(833 \mu \mathrm{g} / \mathrm{mL})$, ACV-MSN $(833 \mu \mathrm{g} / \mathrm{mL})$, and free acyclovir $(42 \mu \mathrm{g} / \mathrm{mL})$ suspended in PBS were mixed with HSV-1 (ca. 35 pfu) diluted with DMEM $2 \%$ FCS and incubated for $1 \mathrm{~h}$. At the tested concentration, ACV-MSN-phenyl-SO $\mathrm{S}_{3}$ would have released ca. $185 \mu \mathrm{g} / \mathrm{mL}$ and ACV-MSN released ca. $200 \mu \mathrm{g} / \mathrm{mL}$ of acyclovir after $1 \mathrm{~h}$ based on the drug release experiment. The suspension was inoculated to Vero cells for $1 \mathrm{~h}$ at $37^{\circ} \mathrm{C}$. The cells were washed twice with PBS to exclude the effects of acyclovir released into the extracellular environment. The suspension was then aspirated and overlayed with 0.6\% CMC in DMEM 2\% FCS at $1 \mathrm{~mL} /$ well. After incubating the plates for 3 days, the cells were fixed, stained, and counted as described above.

Postinfection-To investigate the effect of the loaded acyclovir of ACV-MSN-phenyl-SO ${ }_{3}$, Vero cells $\left(1.2 \times 10^{5}\right.$ cells/well) grown in 24-well plates were infected with HSV-1 (ca. $71 \mathrm{pfu} /$ well), for $2 \mathrm{~h}$ at $37{ }^{\circ} \mathrm{C}$ with $5 \% \mathrm{CO}_{2}$. The extracellular viruses were removed by washing the wells with PBS twice. The cells were then inoculated with ACV-MSNphenyl- $\mathrm{SO}_{3}$ (52 and $104 \mu \mathrm{g} / \mathrm{mL}$ nanoparticle equivalent to approximately 12 and $23 \mu \mathrm{g} / \mathrm{mL}$ acyclovir, respectively, following $1 \mathrm{~h}$ of incubation), acyclovir $(21$ and $42 \mu \mathrm{g} / \mathrm{mL})$, or MSN-phenyl-SO $\mathrm{SO}_{3}(3)$ with a DF of $6 \mathrm{w} / \mathrm{w} \%(208 \mu \mathrm{g} / \mathrm{mL})$ dispersed/dissolved in PBS for $1 \mathrm{~h}$ at $37{ }^{\circ} \mathrm{C}$ with $5 \% \mathrm{CO}_{2}$. The suspension was aspirated and overlayed with $0.6 \% \mathrm{CMC}$ in DMEM 2\% FCS at $1 \mathrm{~mL} /$ well. After incubating the plates for 3 days, the cells were fixed, stained, and counted as described above.

\section{ASSOCIATED CONTENT}

\section{Supporting Information}

The Supporting Information is available free of charge on the ACS Publications website at DOI: 10.1021/acsomega.7b01662.

TGA, XPS, and ${ }^{13} \mathrm{C}$ SSNMR of MSN-phenyl-SO ${ }_{3}$ and $\mathrm{MSN}$-propyl- $\mathrm{SO}_{3}$; characterization of $\mathrm{MSN}-\mathrm{Zw}-\mathrm{SO}_{3}$ and MSN-phenyl; additional antiviral assay results; and characterization, drug release, and antiviral data of acyclovir-loaded nanoparticles (PDF)

\section{AUTHOR INFORMATION}

\section{Corresponding Authors}

*E-mail: n.davispoynter@uq.edu.au (N.D.-P).

*E-mail: b.ross1@uq.edu.au (B.P.R).

ORCID $\odot$

Benjamin P. Ross: 0000-0002-1899-8484

Notes

The authors declare no competing financial interest.

\section{ACKNOWLEDGMENTS}

The authors are grateful for the assistance provided by Dr. Barry Wood (Centre for Microscopy and Microanalysis, UQ) with the operation of XPS. The authors thank Dr. Alice McGovern (School of Biomedical Sciences, UQ) for providing HSV-1 H129 GFP and Cheryl Bletchley for providing the clinical isolate of HSV-2. This work was funded by the School of Pharmacy, UQ. E.C.L. and C.T.H.N. thank UQ for PhD Scholarships.

\section{REFERENCES}

(1) Whitley, R. J.; Roizman, B. Herpes simplex virus infections. Lancet 2001, 357, 1513-1518.

(2) Elion, G. B. Acyclovir: discovery, mechanism of action, and selectivity. J. Med. Virol. 1993, 41, 2-6.

(3) Wilson, S. S.; Fakioglu, E.; Herold, B. C. Novel approaches in fighting herpes simplex virus infections. Expert Rev. Anti-Infect. Ther. 2009, 7, 559-568.

(4) Jenssen, H.; Andersen, J.; Mantzilas, D.; Gutteberg, T. A wide range of medium-sized, highly cationic, $\alpha$-helical peptides show antiviral activity against herpes simplex virus. Antiviral Res. 2004, 64, 119-126.

(5) Spear, P. G. Herpes simplex virus: receptors and ligands for cell entry. Cell. Microbiol. 2004, 6, 401-410.

(6) Mårdberg, K.; Bergström, T.; Glorioso, J. C.; Trybala, E. Mutational analysis of the major heparan sulfate-binding domain of herpes simplex virus type 1 glycoprotein C. J. Gen. Virol. 2001, 82, $1941-1950$

(7) Trybala, E.; Olofsson, S.; Mardberg, K.; Svennerholm, B.; Umemoto, K.; Glorioso, J.; Bergstrom, T. Structural and functional features of the polycationic peptide required for inhibition of herpes simplex virus invasion of cells. Antiviral Res. 2004, 62, 125-134.

(8) Tyssen, D.; Henderson, S. A.; Johnson, A.; Sterjovski, J.; Moore, K.; La, J.; Zanin, M.; Sonza, S.; Karellas, P.; Giannis, M. P.; Krippner, G.; Wesselingh, S.; McCarthy, T.; Gorry, P. R.; Ramsland, P. A.; Cone, R; Paull, J. R. A.; Lewis, G. R.; Tachedjian, G. Structure activity relationship of dendrimer microbicides with dual action antiviral activity. PLoS One 2010, 5, No. e12309.

(9) Shukla, D.; Liu, J.; Blaiklock, P.; Shworak, N. W.; Bai, X.; Esko, J. D.; Cohen, G. H.; Eisenberg, R. J.; Rosenberg, R. D.; Spear, P. G. A novel role for 3-O-sulfated heparan sulfate in herpes simplex virus 1 entry. Cell 1999, 99, 13-22.

(10) Baleux, F.; Loureiro-Morais, L.; Hersant, Y.; Clayette, P.; Arenzana-Seisdedos, F.; Bonnaffé, D.; Lortat-Jacob, H. A synthetic 
CD4-heparan sulfate glycoconjugate inhibits CCR5 and CXCR4 HIV-1 attachment and entry. Nat. Chem. Biol. 2009, 5, 743-748.

(11) Cheshenko, N.; Keller, M. J.; MasCasullo, V.; Jarvis, G. A.; Cheng, H.; John, M.; Li, J.-H.; Hogarty, K.; Anderson, R. A.; Waller, D. P.; Zaneveld, L. J.; Profy, A. T.; Klotman, M. E.; Herold, B. C. Candidate topical microbicides bind herpes simplex virus glycoprotein $\mathrm{B}$ and prevent viral entry and cell-to-cell spread. Antimicrob. Agents Chemother. 2004, 48, 2025-2036.

(12) Gong, E.; Matthews, B.; McCarthy, T.; Chu, J.; Holan, G.; Raff, J.; Sacks, S. Evaluation of dendrimer SPL7013, a lead microbicide candidate against herpes simplex viruses. Antiviral Res. 2005, 68, 139146.

(13) Lembo, D.; Cavalli, R. Nanoparticulate delivery systems for antiviral drugs. Antiviral Chem. Chemother. 2010, 21, 53-70.

(14) Baram-Pinto, D.; Shukla, S.; Perkas, N.; Gedanken, A.; Sarid, R. Inhibition of herpes simplex virus type 1 infection by silver nanoparticles capped with mercaptoethane sulfonate. Bioconjugate Chem. 2009, 20, 1497-1502.

(15) Baram-Pinto, D.; Shukla, S.; Gedanken, A.; Sarid, R. Inhibition of HSV-1 attachment, entry, and cell-to-cell spread by functionalized multivalent gold nanoparticles. Small 2010, 6, 1044-1050.

(16) Baram-Pinto, D.; Shukla, S.; Richman, M.; Gedanken, A.; Rahimipour, S.; Sarid, R. Surface-modified protein nanospheres as potential antiviral agents. Chem. Commun. 2012, 48, 8359-8361.

(17) Lee, E. C.; Davis-Poynter, N.; Nguyen, C. T. H.; Peters, A. A.; Monteith, G. R.; Strounina, E.; Popat, A.; Ross, B. P. GAG mimetic functionalised solid and mesoporous silica nanoparticles as viral entry inhibitors of herpes simplex type 1 and type 2 viruses. Nanoscale 2016, 8, 16192-16196.

(18) Rosenholm, J. M.; Sahlgren, C.; Lindén, M. Towards multifunctional, targeted drug delivery systems using mesoporous silica nanoparticles-opportunities \& challenges. Nanoscale 2010, 2, $1870-1883$

(19) Luo, Z.; Cai, K.; Hu, Y.; Zhang, B.; Xu, D. Cell-specific intracellular anticancer drug delivery from mesoporous silica nanoparticles with $\mathrm{pH}$ sensitivity. Adv. Healthcare Mater. 2012, 1, 321-325.

(20) Radu, D. R.; Lai, C.-Y.; Jeftinija, K.; Rowe, E. W.; Jeftinija, S.; Lin, V. S.-Y. A polyamidoamine dendrimer-capped mesoporous silica nanosphere-based gene transfection reagent. J. Am. Chem. Soc. 2004, 126, 13216-13217.

(21) Maniya, N. H.; Patel, S. R.; Murthy, Z. V. P. Development and in vitro evaluation of acyclovir delivery system using nanostructured porous silicon carriers. Chem. Eng. Res. Des. 2015, 104, 551-557.

(22) Tamayo, A.; Mazo, M. A.; Ruiz-Caro, R; Martín-Illana, A.; Bedoya, L. M.; Veiga-Ochoa, M. D.; Rubio, J. Mesoporous silicon oxycarbide materials for controlled drug delivery systems. Chem. Eng. J. 2015, 280, 165-174.

(23) Jain, S.; Mistry, M. A.; Swarnakar, N. K. Enhanced dermal delivery of acyclovir using solid lipid nanoparticles. Drug Delivery Transl. Res. 2011, 1, 395-406.

(24) Ensign, L. M.; Tang, B. C.; Wang, Y.-Y.; Tse, T. A.; Hoen, T.; Cone, R; Hanes, J. Mucus-penetrating nanoparticles for vaginal drug delivery protect against herpes simplex virus. Sci. Transl. Med. 2012, 4, 138 ra179.

(25) Giannavola, C.; Bucolo, C.; Maltese, A.; Paolino, D.; Vandelli, M. A.; Puglisi, G.; Lee, V. H. L.; Fresta, M. Influence of preparation conditions on acyclovir-loaded poly-d,l-lactic acid nanospheres and effect of PEG coating on ocular drug bioavailability. Pharm. Res. 2003, 20, 584-590.

(26) Bareiss, B.; Ghorbani, M.; Li, F.; Blake, J. A.; Scaiano, J. C.; Zhang, J.; Deng, C.; Merrett, K.; Harden, J. L.; Diaz-Mitoma, F.; Griffith, M. Controlled release of acyclovir through bioengineered corneal implants with silica nanoparticle carriers. Open Tissue Eng. Regener. Med. J. 2010, 3, 10-17.

(27) Cavalli, R.; Donalisio, M.; Civra, A.; Ferruti, P.; Ranucci, E.; Trotta, F.; Lembo, D. Enhanced antiviral activity of Acyclovir loaded into $\beta$-cyclodextrin-poly(4-acryloylmorpholine) conjugate nanoparticles. J. Controlled Release 2009, 137, 116-122.
(28) Kim, T.-W.; Chung, P.-W.; Lin, V. S.-Y. Facile Synthesis of Monodisperse Spherical MCM-48 Mesoporous Silica Nanoparticles with Controlled Particle Size. Chem. Mater. 2010, 22, 5093-5104.

(29) Gibson, N.; Shenderova, O.; Luo, T. J. M.; Moseenkov, S.; Bondar, V.; Puzyr, A.; Purtov, K.; Fitzgerald, Z.; Brenner, D. W. Colloidal stability of modified nanodiamond particles. Diamond Relat. Mater. 2009, 18, 620-626.

(30) Cano-Serrano, E.; Blanco-Brieva, G.; Campos-Martin, J. M.; Fierro, J. L. G. Acid-functionalized amorphous silica by chemical grafting-quantitative oxidation of thiol groups. Langmuir 2003, 19, $7621-7627$.

(31) Lin, Y.-S.; Haynes, C. L. Impacts of mesoporous silica nanoparticle size, pore ordering, and pore integrity on hemolytic activity. J. Am. Chem. Soc. 2010, 132, 4834-4842.

(32) Hoffmann, F.; Cornelius, M.; Morell, J.; Fröba, M. Silica-based mesoporous organic-inorganic hybrid materials. Angew. Chem., Int. Ed. 2006, 45, 3216-3251.

(33) Lee, C.-H.; Cheng, S.-H.; Huang, I.-P.; Souris, J. S.; Yang, C.-S.; Mou, C.-Y.; Lo, L.-W. Intracellular pH-responsive mesoporous silica nanoparticles for the controlled release of anticancer chemotherapeutics. Angew. Chem., Int. Ed. 2010, 49, 8214-8219.

(34) Luo, G.-F.; Chen, W.-H.; Liu, Y.; Zhang, J.; Cheng, S.-X.; Zhuo, R.-X.; Zhang, X.-Z. Charge-reversal plug gate nanovalves on peptidefunctionalized mesoporous silica nanoparticles for targeted drug delivery. J. Mater. Chem. B 2013, 1, 5723.

(35) Minati, L.; Antonini, V.; Serra, M. D.; Speranza, G.; Enrichi, F.; Riello, P. pH-activated doxorubicin release from polyelectrolyte complex layer coated mesoporous silica nanoparticles. Microporous Mesoporous Mater. 2013, 180, 86-91.

(36) Nazemi, A.; Haeryfar, S. M. M.; Gillies, E. R. Multifunctional dendritic sialopolymersomes as potential antiviral agents: their lectin binding and drug release properties. Langmuir 2013, 29, 6420-6428.

(37) Park, P. J.; Antoine, T. E.; Farooq, A. V.; Valyi-Nagy, T.; Shukla, D. An investigative peptide-acyclovir combination to control herpes simplex virus type 1 ocular infection. Invest. Ophthalmol. Visual Sci. 2013, 54, 6373-6381.

(38) Shukla, D.; Spear, P. G. Herpesviruses and heparan sulfate: an intimate relationship in aid of viral entry. J. Clin. Invest. 2001, 108, $503-510$.

(39) McGovern, A. E.; Davis-Poynter, N.; Rakoczy, J.; Phipps, S.; Simmons, D. G.; Mazzone, S. B. Anterograde neuronal circuit tracing using a genetically modified herpes simplex virus expressing EGFP. J. Neurosci. Methods 2012, 209, 158-167.

(40) Estephan, Z. G.; Schlenoff, P. S.; Schlenoff, J. B. Zwitteration as an alternative to PEGylation. Langmuir 2011, 27, 6794-6800. 